\title{
Sacrocolpopexy without concomitant posterior repair improves posterior compartment defects
}

\author{
Maryam Guiahi $\cdot$ Kimberly Kenton $\cdot$ Linda Brubaker
}

Received: 6 December 2007 / Accepted: 24 March 2008 / Published online: 22 May 2008

(C) The Author(s) 2008

\begin{abstract}
The aim of this study is to determine posterior compartment topography 1-year after sacrocolpopexy (SC). Women who had SC without concomitant anterior or posterior repairs for symptomatic pelvic organ prolapse (POP) were included. Vaginal topography was assessed at baseline and 1-year postoperatively using POP quantification (POPQ). At baseline, 24\% had stage IV POP, 68\% stage III, and $8 \%$ stage II. One year after surgery, $75 \%$ had stage $0 /$ I POP, $24 \%$ stage II, and 1\% stage III. 112 (75\%) were objectively cured (stage 0 or I POP). Anterior compartment was the most common site of POP persistence or recurrence $(\mathrm{Ba} \geq$ stage II in 23 women) followed by posterior compartment ( $\mathrm{Bp} \geq$ stage II in 12 women) and apex ( $\mathrm{C} \geq$ stage II in 2 women). In 1-year follow-up, SC without concomitant posterior repair restores posterior vaginal topography in the majority of women with undergoing SC.
\end{abstract}

Keywords Posterior compartment · Sacrocolpopexy ·

Pelvic organ prolapse $\cdot$ Rectocele

\section{Introduction}

The optimal approach for surgical correction of pelvic organ prolapse (POP) remains unclear. Reported POP recurrence or persistence rates after reconstructive surgery

M. Guiahi $\cdot$ K. Kenton $(\bowtie) \cdot$ L. Brubaker

Division of Female Pelvic Medicine and Reconstructive Surgery,

Departments of Obstetrics and Gynecology and Urology,

Loyola University Medical Center,

2160 South First Avenue,

Maywood, IL 60153, USA

e-mail: kkenton@lumc.edu are nearly $60 \%$ at 1 year [1] with reoperation rates as high as $30 \%$ [2]. Isolated defects in a single vaginal compartment are uncommon in women with apical POP [3-5] and $76 \%$ of women with multiple compartment defects may have posterior compartment POP [6]. Surgeons disagree whether it is necessary to perform concomitant posterior repair and/or perineorrhaphy in women undergoing surgery for apical POP. Many surgeons perform a concomitant posterior repair at the time of apical repair to restore posterior vaginal wall topography [7-10], while others believe adequate resuspension of the apex will correct many posterior compartment defects [11, 12]. While posterior repair has been shown to improve posterior vaginal topography, it is associated with high rates of dyspareunia and variable improvement in defecatory dysfunction. [13-16] As a result, pelvic surgeons have increasingly focused on correcting the vaginal apex, believing that apical correction will improve posterior compartment topography as well.

The aim of our study was to determine posterior vaginal topography 1 year after abdominal sacrocolpopexy (SC) without concomitant posterior repair or perineorrhaphy for advanced prolapse (POP).

\section{Materials and methods}

After Institutional Review Board approval, we reviewed consecutive inpatient and outpatient charts of women who underwent abdominal SC for POP and who were not enrolled in other clinical trials between July 2000 and August 2005 at Loyola University Medical Center. We reviewed operative notes to confirm surgical procedures. Study women all underwent abdominal SC in a standardized fashion. A "Y" piece of mersilene mesh was attached 
to the posterior vagina down to the rectal reflection (this distance varied depending on the subject's vaginal length) and to the anterior vagina for a distance of 3-4 cm using two rows of cv-2 Gore-Tex ${ }^{\circledR}$ sutures. Concomitant hysterectomies were performed in women with a uterus, and concomitant continence surgeries were done according to patients' symptoms and urodynamic findings. Surgeries were done by residents and fellows under the direct supervision of two attending urogynecologic surgeons. Women with concomitant compartment specific repairs, i.e., posterior or anterior vaginal wall surgeries, were excluded.

All women underwent objective POP assessment in the supine and standing strain positions using the POP quantified (POPQ) system at baseline and 1 year after surgery. Points tvl, pb, and genital hiatus (gh) were measured with the patients' supine, while the remaining POPQ points were measured with patients standing at maximal strain. Baseline and 1-year POP-Q assessments were done by fellows or attending urogynecologists. Women were included in the final analysis if complete baseline and 1-year POP-Q data were recorded. Objective cure was defined as stage 0 or I POP in all vaginal compartments 1 year after surgery; if any vaginal compartment was greater than or equal to stage II, the surgery was considered an objective failure. We abstracted demographic characteristics, body mass index, surgical history, obstetric history, urogynecologic findings, smoking history, intraoperative, and postoperative complications from the charts.

Statistical Package for the Social Sciences (Version 13) was used for data management and analysis. Wilcoxon Signed Ranks Test was used to compare baseline and postoperative POPQ points. Mann-Whitney test was used to compare POPQ points between independent groups. All tests were considered significant at the. 05 level and no onesided tests were used.

\section{Results}

Two hundred women underwent SC during the study period. One hundred forty-nine women had baseline and 1 -year POPQ data and were included in the final analysis. Four had concomitant anterior or posterior repair and were excluded. Tables 1 and 2 list the demographic character-

Table 1 Demographic history

\begin{tabular}{lcc}
\hline & Mean + SD & Median (range) \\
\hline Age & $56+15$ & \\
BMI & $27+7$ & $3(0-10)$ \\
Parity & & 3 \\
\hline
\end{tabular}

Table 2 Demographic and surgical histories

\begin{tabular}{lr}
\hline Prior surgery & (Number (\%)) \\
\hline Prolapse & $72(54)$ \\
Incontinence & $34(25)$ \\
Hysterectomy (Can include prolapse & $131(89)$ \\
$\quad$ and/or incontinence) & \\
Race (\%) & \\
Caucasian & $(88)$ \\
Hispanic & $(9)$ \\
African-American & $(3)$ \\
\hline
\end{tabular}

istics and surgical histories of this cohort. At baseline, 35 women $(24 \%)$ had stage IV POP, $102(69 \%)$ stage III, and $12(8 \%)$ stage II. Half of women (54\%) had a concomitant continence procedure at the time of SC; $40 \%$ had a Burch colposuspension and $14 \%$ had a fascial sling. Twelve percent of women had a concomitant abdominal hysterectomy.

One year after surgery, 112 women $(75 \%)$ were objectively cured (stage 0 or I POP), and 37 (25\%) were considered objective failures. All but two women who met criteria for objective failure had stage II POP; the remaining two women had stage III POP. The most common site of failure was the anterior compartment $(\mathrm{Ba} \geq$ stage II in 23 women), followed by posterior compartment (Bp $\geq$ stage II in 12 women), and the apex ( $\mathrm{C} \geq$ stage II in 2 women). One woman with stage III prolapse had a reoperation in the first year consisting of an anterior and posterior colporrhaphy.

Table 3 shows baseline and 1-year postoperative measurements for the position of the apex (point $\mathrm{C}$ ), the most prolapse point on the anterior $(\mathrm{Ba})$ and posterior $(\mathrm{Bp})$ vaginal walls, and the gh. The position of the apex, most prolapsed points on the anterior $(\mathrm{Ba})$ and posterior $(\mathrm{Bp})$ vagina, and gh were all significantly improved after SC without posterior repair or perineorrhaphy. There was no significant change in the total vaginal length or perineal body size (.243 and .395 , respectively). While postoperative POPQ points $\mathrm{Ba}$ and $\mathrm{Bp}$ were significantly more

Table 3 Baseline and postoperative POPQ points

\begin{tabular}{lccc}
\hline & $\begin{array}{l}\text { Baseline } \\
(\text { mean } \pm \mathrm{SD})\end{array}$ & $\begin{array}{l}\text { 1-year Postoperative } \\
(\text { mean } \pm \mathrm{SD})\end{array}$ & $P$ value \\
\hline $\mathrm{Ba}(\mathrm{cm})$ & $3.5 \pm 2.7$ & $-2 \pm 1$ & $<.0005$ \\
$\mathrm{C}(\mathrm{cm})$ & $1 \pm 5$ & $-9 \pm 2$ & $<.0005$ \\
$\mathrm{Ap}(\mathrm{cm})$ & $-0.3 \pm 2.5$ & $-2 \pm 1$ & $<.0005$ \\
$\mathrm{Bp}(\mathrm{cm})$ & $1 \pm 3.6$ & $-2 \pm 1$ & $<.0005$ \\
$\mathrm{Gh}(\mathrm{cm})$ & $4 \pm 2$ & $3 \pm 1$ & .001 \\
\hline
\end{tabular}


prolapsed in women who met criteria for objective failure (Ba $-1+1$ versus $-2.5+0.7, P<.0005$ and $\mathrm{Bp}-1.6+1$ versus $-2+1, P=.038$ ), the difference in point $\mathrm{Bp}$ was not clinically significant. No other postoperative or baseline POPQ points were significantly different between cure groups.

There were no significant differences in objective cure or overall POPQ stage at 1 year in women who did and did not have a concomitant continence procedure $(p=.992$ and $p=.762$, respectively). Both anterior vaginal wall POPQ points were significantly more prolapsed in women who did not undergo a concomitant continence procedure when compared to those who had a Burch or sling (Aa: $-1.6+1$ versus $-2.2+1.1, P=.02$; and $\mathrm{Ba}:-1.6+1$ versus $-2.1+1.4$, $P=.03$ ). Posterior vaginal wall POPQ points were not different in women who did and did not undergo continence procedures $(P=.43$ and $P=.31)$.

\section{Discussion}

Our data indicate that SC without concomitant posterior repair or perineorrhaphy restores posterior compartment topography in most women. While $61 \%$ of women had $\geq$ stage II posterior compartment POP prior to SC, only $8 \%$ had $\geq$ stage II posterior POP 1 year after SC without concomitant posterior repair or perineorrhaphy. Only one woman chose reoperation for posterior POP. Our posterior vaginal compartment recurrent or persistent POP rates after SC alone are consistent with those reported after SC and selective posterior repair or perineorrhaphy. Benson et al. reported anatomic outcomes in 38 women who underwent $\mathrm{SC}$ with selective posterior compartment repairs as part of a randomized trial of abdominal versus vaginal POP surgery [8]. Sixty-five percent of women had posterior colporrhaphy in addition to $\mathrm{SC}$ with two women requiring reoperation for posterior compartment POP at a mean of 22 months after surgery. Similarly, Culligan et al. [17] reported POPQ outcomes for 245 women who had SC with selective concomitant procedures; $25 \%$ had concomitant posterior repairs or perineorrhaphies. By 1 year, $6 \%$ of subjects had $\geq$ stage II posterior compartment prolapse, similar to $8 \%$ in our patients. Maher et al. [10] had similar results in women with vault POP at or beyond the introitus who underwent SC. Seventy-four percent also had a grade II rectocele, and 23\% underwent concomitant posterior repair. Postoperatively, $17 \%$ had a persistent grade II rectocele.

There may be disadvantages to performing concomitant posterior repair. Dyspareunia rates after traditional posterior colporrhaphy have been reported to be as high as $21 \%$ [18, 19], although de novo dyspareunia rates after site-specific posterior repair are lower ranging from $1-7 \%[13,14]$. Most studies are limited by multiple POP procedures being done, concomitantly making it difficult to determine the precise etiology for new symptoms. However, given the lack of clear advantage to concomitant posterior repair or perineorrhaphy at the time of SC, surgeons should perform these additional procedures judiciously.

Genital hiatus size is thought to contribute to posterior compartment symptoms and reflect perineal descent [11, 20]. In a cohort of women with POP, Fialkow et al. [20] found the only difference between women with and without posterior compartment symptoms was genital hiatus size; women with posterior symptoms had a genital hiatus larger than $3 \mathrm{~cm}$, resulting in perineal descent of more than $2 \mathrm{~cm}$. Other investigators have shown a decrease in genital hiatus size of $1-1.5 \mathrm{~cm}$ after SC with selective posterior repair and perineorrhaphy without a significant change in perineal body size $[11,17]$. They hypothesize that this reflects restoration of perineal descent and may be associated with improvement in posterior compartment symptoms [11]. Our patients had a similar decrease in genital hiatus size without a significant increase in perineal body size without concomitant posterior repair or perineorrhaphy further questioning the benefit of additional posterior vaginal wall repair at the time of SC.

We did not collect symptom or quality of life data on women in this cohort as our primary question was simply to address vaginal anatomy, so we cannot comment on the posterior compartment symptomatic improvement after SC alone. The relationship between posterior vaginal compartment anatomic defects and posterior compartment symptoms, such as splinting, straining, constipation, and incomplete evacuation remains unclear. Multiple studies have not found a significant association between posterior compartment anatomy and most bowel symptoms $[3,21$, 22]. However, others have reported that difficulty with evacuation [20], splinting [20], and constipation [23] are more common in women with POP.

The role of concomitant posterior repair and perineorrhaphy at the time of apical repair warrants further investigation with randomized trials. Case-series data indicate that posterior topography improves after SC similarly when posterior repairs and perineorrhaphies are done selectively or not at all. Women undergoing SC can be counseled that a discrete posterior vaginal operation is not always necessary for restoration of posterior vaginal topography.

\section{Conflicts of interest None.}

Open Access This article is distributed under the terms of the Creative Commons Attribution Noncommercial License which permits any noncommercial use, distribution, and reproduction in any medium, provided the original author(s) and source are credited. 


\section{References}

1. Whiteside JL, Weber AM, Meyn LA, Walters MD (2004) Risk factors for prolapse recurrence after vaginal repair. Am J Obstet Gynecol 191:1533-1538

2. Olsen AL, Smith VJ, Bergstrom JO, Colling JC, Clark AL (1997) Epidemiology of surgically managed pelvic organ prolapse and urinary incontinence. Obstet Gynecol 89(4):501-506

3. Bradley CS, Brown MB, Cundiff GW, Goode PS, Kenton KS, Nygaard IE, Whitehead WE, Wren PA, Weber AM, Pelvic Floor Disorders N (2006) Bowel symptoms in women planning surgery for pelvic organ prolapse. Am J Obstet Gynecol 195(6):18141819

4. Brown JS, Waetjen E, Subak LL, Thom DH, Van Den Eeden SK, Vittinghoff E (2002) Pelvic organ prolapse surgery in the United States, 1997. Am J Obest Gynec 186(4):711-716

5. Rooney K, Kenton K, Mueller ER, FitzGerald MP, Brubaker L (2006) Advanced anterior vaginal wall prolapse is highly correlated with apical prolapse. Am J Obstet Gynecol 195 (6): $1837-1840$

6. DeLancey JO (1999) Structural anatomy of the posterior pelvic compartment as it relates to rectocele. Am J Obstet Gynecol 180 (4):815-823

7. Addison WA, Livengood CH 3rd, Sutton GP, Parker RT (1985) Abdominal sacral colpopexy with Mersilene mesh in the retroperitoneal position in the management of posthysterectomy vaginal vault prolapse and enterocele. Am J Obstet Gynecol 153 (2):140-146

8. Benson JT, Lucente V, McClellan E (1996) Vaginal versus abdominal reconstructive surgery for the treatment of pelvic support defects: a prospective randomized study with long-term outcome evaluation. Clinical Trial. Journal Article. Randomized Controlled Trial. Am J Obstet Gynecol 175(6):1418-1421 discussion 1421-1412

9. Feldman GB, Birnbaum SJ (1979) Sacral colpopexy for vaginal vault prolapse. Obstetrics Gynecology 53(3):399-401

10. Maher CF, Qatwneh A, Dwyer PL, Carey MP, Cornish A, Schluter P (2004) Abdominal sacral colpopexy or vaginal sacrospinous colpopexy for vaginal vault prolapse. A prospective randomized trial. Am J Obstet Gynecol 190:20-26

11. Cundiff GW, Harris RL, Coates K, Low VH, Bump RC, Addison WA (1997) Abdominal sacral colpoperineopexy: a new approach for correction of posterior compartment defects and perineal descent associated with vaginal vault prolapse. Am J Obstet Gynecol 177(6):1345-1353 discussion 1353-1345

12. Snyder TE, Krantz KE (1991) Abdominal-retroperitoneal sacral colpopexy for the correction of vaginal prolapse. comment. Am J Obstet Gynecol 77(6):944-949

13. Kenton K, Shott S, Brubaker L (1999) Outcome after rectovaginal fascia reattachment for rectocele repair. Am J Obstet Gynecol 181 (6):1360-1363 discussion 1363-1364

14. Cundiff GW, Weidner AC, Visco AG, Addison WA, Bump RC (1998) An anatomic and functional assessment of the discrete defect rectocele repair. Am J Obstet Gynecol 179(6 Pt 1):14511456 discussion $1456-1457$

15. Kahn MA, Stanton SL (1998) Techniques of Rectocele Repair and their Effects on Bowel Function. Int Urogyn J 9:37-47

16. Mellgren A, Anzen B, Nilsson BY, Johansson C, Dolk A, Gillgren P, Bremmer S, Holstrom B (1995) Results of rectocele repair: A prospective study. Dis Colon Rectum 38:7-13

17. Culligan PJ, Murphy M, Blackwell L, Hammons G, Graham C, Heit MH (2002) Long-term success of abdominal sacral colpopexy using synthetic mesh. Am J Obstet Gynecol 187(6):14731480 discussion $1481-1472$

18. Kahn MA, Stanton SL (1997) Posterior colporrhaphy: its effects on bowel and sexual function. Br J Obstet Gynaecol 104(1):82-86

19. Arnold MW, Stewart WR, Aguilar PS (1990) Rectocele repair Four years' experience. Dis Colon Rectum 33(8):684-687

20. Fialkow MF, Gardella C, Melville J, Lentz GM, Fenner DE (2002) Posterior vaginal wall defects and their relation to measures of pelvic floor neuromuscular function and posterior compartment symptoms. Am J Obstet Gynecol 187(6):1443-1448 discussion $1448-1449$

21. Klingele CJ, Bharucha AE, Fletcher JG, Gebhart JB, Riederer SG, Zinsmeister AR (2005) Pelvic organ prolapse in defecatory disorders. Obstet Gynecol 106(2):315-320

22. Kahn MA, Breitkopf CR, Valley MT, Woodman PJ, O'Boyle AL, Bland DI, Schaffer JI, Grady JJ, Swift SE (2005) Pelvic Organ Support Study (POSST) and bowel symptoms: straining at stool is associated with perineal and anterior vaginal descent in a general gynecologic population. Am J Obstet Gynecol 192 (5):1516-1522

23. Arya LA, Novi JM, Shaunik A, Morgan MA, Bsradley CS (2005) Pelvic organ prolapse, constipation, and dietary fiber intake in women: a case-control study. Am J Obstet Gynecol 192(5):1687-1691 